\title{
OS PROCESSOS DE FORMAÇÃO DO REGISTRO ARQUEOLÓGICO NO SÍTIO ARQUEOLÓGICO LAGOA DA JUREMA, RIO GRANDE DO NORTE, BRASIL.
}

\author{
Valdeci dos Santos Júnior ${ }^{i}$ \\ Alano Jaciguara Dantas de Alencar Martins ${ }^{\mathrm{ii}}$ \\ Daline Lima de Oliveira ${ }^{\mathrm{iii}}$
}

'Professor do Departamento de História, Universidade do Estado do Rio Grande do Norte (UERN) valdecisantosjr@hotmail.com

ii Mestrando em Geografia,
Universidade do Estado do Rio
Grande do Norte (UERN)
Jaciguara@ymail.com

iii Mestranda em Arqueologia, Universidade Federal do Piauí (UFPI) daline_bs@hotmail.com
Resumo: Este artigo apresenta os resultados do resgate do sítio arqueológico Lagoa da Jurema, localizado na região do Vale do Assú, Estado do Rio Grande do Norte, analisando os contextos de deposição dos vestígios culturais que possibilitaram a construção de inferências sobre os processos de formação do registro arqueológico daquela ocupação humana pretérita. A metodologia utilizada constou de intervenções sistemáticas com escavações para a coleta de dados dos registros arqueológicos, sendo efetuadas pesquisas bibliográficas, imagéticas e elaboração de mapas temáticos. A análise dos resultados indicou uma quase exclusividade dos vestígios líticos lascados coletados em nível de superfície, permitindo supor ocupações temporárias diacrônicas por grupos humanos pretéritos para obtenção de água, aliadas a possíveis atividades de pesca e caça da pequena fauna local.

Palavras-Chave: Palavras-chave: Processos de formação do registro arqueológico, Artefatos líticos, Ocupação humana pretérita no Vale do Assú..

Abstract: This article presents the results of the rescue of the archaeological site Lagoa da Jurema, located in the municipality of Assú, analyzing the contexts of deposition of cultural remains that enabled the construction of inferences about the formation processes of the archaeological record in the past human occupation in the Vale region do Assú, State of Rio Grande do Norte. The methodology used consisted of systematic interventions with excavations with the collection of data from the archaeological records, with bibliographic, imagery and thematic maps being made. The analysis of the results indicated an almost exclusivity of the chipped lithic traces collected at the surface level, allowing the supposition of temporary diachronic occupations by past human groups to obtain water, together with possible fishing and hunting activities of the small local fauna.

Key Words: Formation processes of the archaeological record, Lytic artefacts, past human occupation in the Assú Valley. 


\section{Introdução}

O sítio arqueológico Lagoa da Jurema está localizado no município de Açu - RN, na mesorregião do Oeste Potiguar, microrregião do Vale do Açu (Figura 1). Trata-se de um sítio a céu aberto, tendo como ponto central de georreferenciamento as coordenadas (Datum SIRGAS 2000) UTM 24 M E 0718305,150 e S 9382685,080, a uma cota altimétrica média de 86.00 m, distando a 12,6 km (na direção E) da zona urbana de Açu-RN.

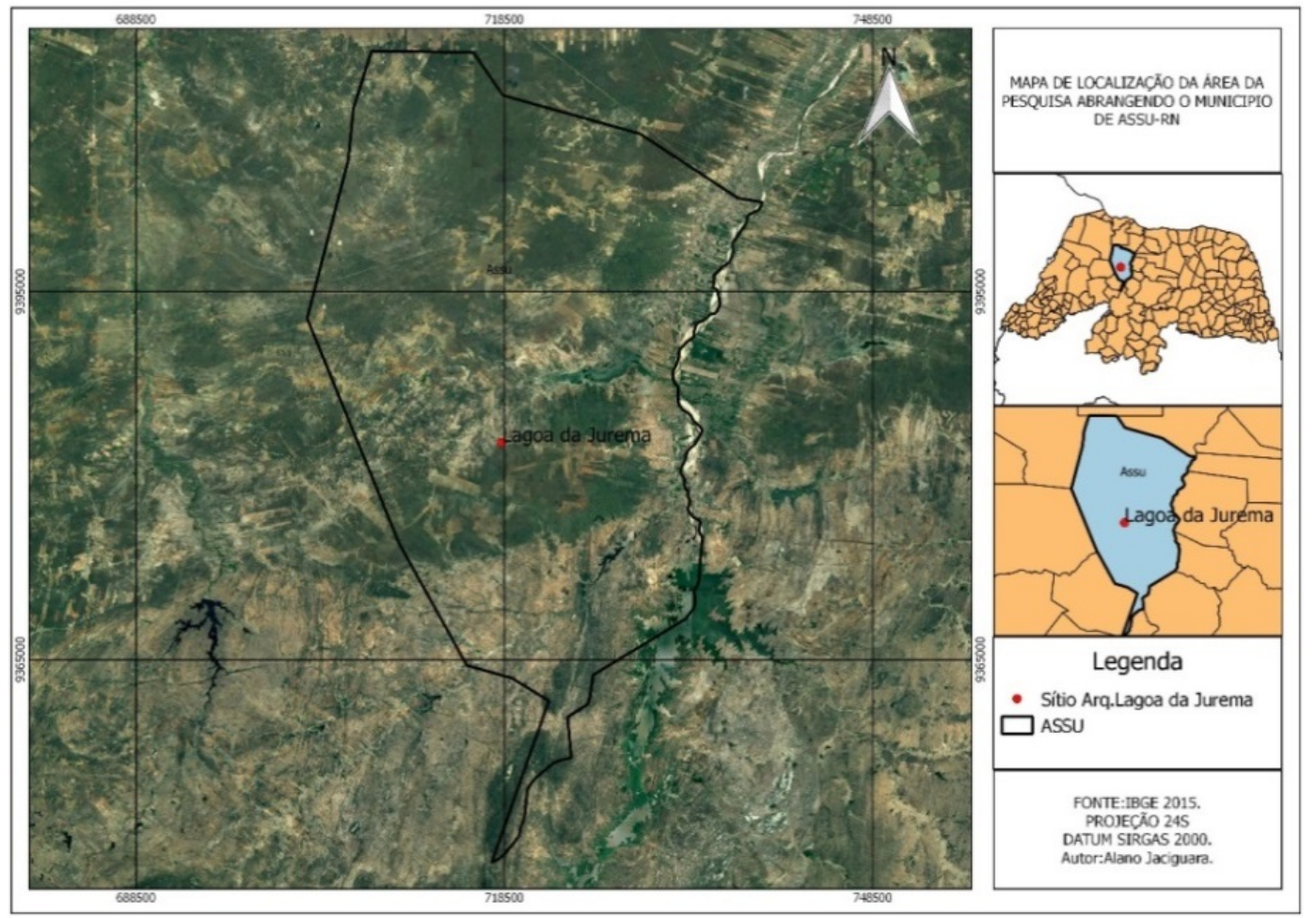

Figura 1: Localização do sítio arqueológico Lagoa da Jurema, município de Açu - RN, na mesorregião do Oeste Potiguar, microrregião do Vale do Açu. Fonte: IBGE, 2015, adaptado por Alano Jaciguara, 2020.

O sítio foi identificado inicialmente em 2015, na fase do diagnóstico do Projeto de Salvamento Arqueológico da Linha de Transmissão 500 kV Milagres II - Açu III. Na fase posterior (resgate), realizado também em 2015, em que um dos objetivos das intervenções arqueológicas foi caracterizar e compreender a ocupação pretérita do sítio arqueológico Lagoa da Jurema, a partir da correlação entre os vestígios de origem antrópica (sobretudo artefatos líticos) e o contexto ambiental em que estavam inseridos. A intenção da análise era privilegiar a interface entre o ambiente e as ocupações diacrônicas pelas populações pretéritas do espaço geográfico da lagoa (Figuras 2 e 3), que poderia permitir um melhor entendimento das dinâmicas de ocupação do território, além de auxiliar nos estudos paleogeográficos de caráter local e regional. 


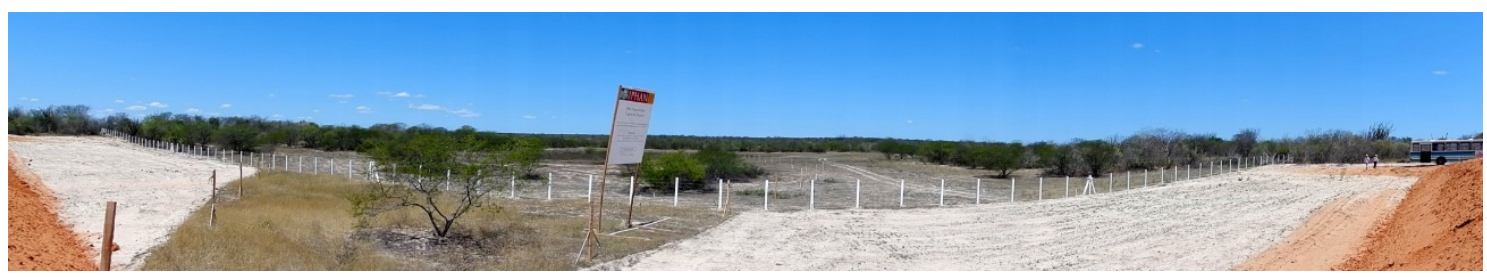

Figura 2: Visão panorâmica (microambiental) do sítio arqueológico Lagoa da Jurema, município de Açu RN (Sentido Norte-Sul). Fonte: Santos Júnior, 2015.

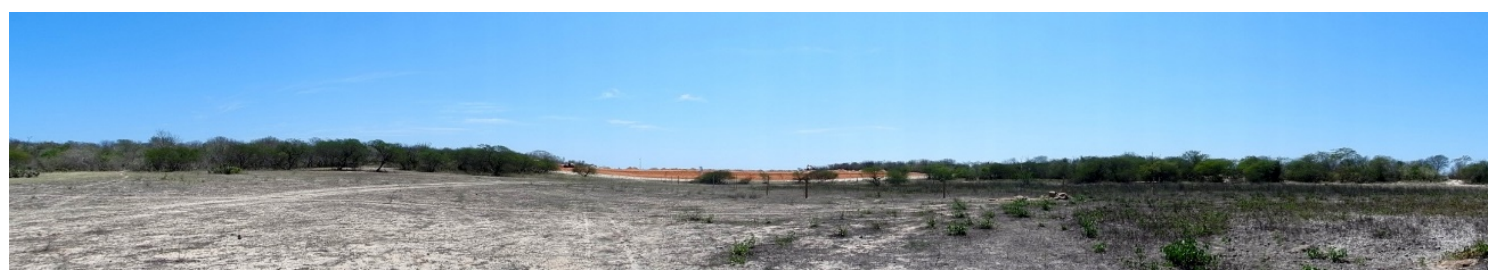

Figura 3: Visão panorâmica (microambiental) do sítio arqueológico Lagoa da Jurema, município de AçuRN (Sentido Sul-Norte). Fonte: Alano Jaciguara, 2015.

A pesquisa salientou também a necessidade de situar, no sentido estratigráfico, os vestígios arqueológicos face aos processos naturais e culturais responsáveis pelo seu soterramento, além da verificação de possíveis hiatos temporais nos processos de formação dos registros arqueológicos na lagoa.

\section{Hipóteses preliminares}

As hipóteses de trabalho que orientaram as escavações e resgate na área do sítio arqueológico foram norteadas por duas vertentes: as relacionadas à integridade do registro arqueológico (grau de preservação dos arranjos de superfície), expostos que foram aos processos pluviais/fluviais de transporte/deposição; e às relacionadas aos conjuntos de cultura material, aos arranjos espaciais e demais vestígios de atividade identificados na área da lagoa.

Quanto à integridade do registro, foi testada a possibilidade de ocorrência de contextos arqueológicos de subsuperfície não perturbados pelos processos pluviais/fluviais, uma vez que foram evidenciados contextos de superfície, compostos por artefatos e demais vestígios de atividade na área do empreendimento ${ }^{1}$.

Quanto ao teste das hipóteses suscitadas pelas características da cultura material identificada e principalmente sobre a sua estrutura e os seus arranjos espaciais que conformam áreas de

\footnotetext{
${ }^{1}$ Ressalte-se que o contexto da área de instalação é composto por área de lagoa, nesta o registro arqueológico é frequentemente alterado por modificações pós-deposicionais, devido a fatores naturais (climáticas e bioturbação) e culturais (ações antrópicas) (nota dos autores).
} 
refugo ou de atividade, esta estruturação foi interpretada também como uma forma de cultura material ${ }^{2}$.

Assim, as hipóteses sobre a cultura material e os arranjos espaciais no sítio foram testadas, a partir de uma perspectiva de análise intra-sítio, as questões a serem respondidas pelo estudo arqueológico diziam respeito a: 1) Se os refugos foram depositados nos exatos locais onde as atividades pretéritas foram desenvolvidas; 2) Se os arranjos espaciais no sítio refletiam materialmente padrões de uso e descarte nas áreas de atividade, documentando as formas de disposição e arranjo do sistema cultural pretérito; 3) Se os contextos deposicionais e demais arranjos espaciais refletiriam todas ou apenas as atividades da ocupação final no sítio; 4) Se a duração da ocupação humana no sítio é refletida pela distribuição/densidade das áreas de refugo; e 5) Se os padrões expressos pela cultura material e seus arranjos espaciais identificariam culturalmente o (s) grupo (s) que ocupou/ocuparam o sítio.

\section{Metodologia}

O resgate do sítio se deu através da coleta de dados do registro arqueológico com o recurso das seguintes intervenções: a) Prospeç̧ão de superfície para delimitação da área de dispersão dos vestígios, bem como a existência ou não de fontes de matéria-prima, para estabelecer a dimensão exata da área de intervenção do salvamento; b) Levantamento topográfico da área de ocorrência de artefatos e demais vestígios de atividade humana pretérita com a utilização de estação total; c) Escavação de subsuperfície, através de sondagens e trincheiras, com dimensões variáveis, de acordo com a distribuição de vestígios arqueológicos em superfície; d) Coleta sistemática de cultura material, por meio de plotagem individual com estação total; e) Registro Imagético de todas as atividades realizadas no sítio, bem como do contexto anterior e posterior ao resgate.

Foram realizadas quatro sondagens (denominadas sondagens 01, 02, 03 e 04) e cinco trincheiras (denominadas trincheiras A, B, C, D e E); as dimensões das sondagens variaram: a sondagem 1 possuía a dimensão de $7 \mathrm{~m} \times 4 \mathrm{~m}$; a sondagem $2,5 \mathrm{~m} \times 2 \mathrm{~m}$; a sondagem 3, com 15 $\mathrm{m} \times 5 \mathrm{~m}$; e a sondagem 4 com $5 \mathrm{~m} \times 2 \mathrm{~m}$. (Figura 4). As profundidades atingiram até $50 \mathrm{~cm}$. As

\footnotetext{
${ }^{2}$ Vestígios culturais provenientes de atividade, artefatos ou estruturas relacionadas às ocupações pré-coloniais e históricas (nota dos autores).
} 
dimensões de todas as trincheiras foram iguais, de $10 \mathrm{~m} \times 1 \mathrm{~m}$, com profundidades variáveis entre 20 a $23 \mathrm{~cm}$.



Figura 4: Perímetro delimitado e localização espacial das sondagens e trincheiras efetuadas no sítio arqueológico Lagoa da Jurema - município de Açu-RN. Fonte: Daniel Kim, 2015.

\section{Quantitativo de vestígios arqueológicos}

O acervo arqueológico coletado foi composto por um total de 180 artefatos, divididos entre os vestígios culturais coletados em nível de superfície (178), vestígios recuperados em nível de subsuperfície (1) e vestígios oriundos do peneiramento (1) de sedimentos da sondagem 3. A tipologia desse acervo coletado apresentou os seguintes dados: a) 174 vestígios líticos; b) 5 vestígios de fragmentos cerâmicos; c) 1 vestígio de fragmento de louça.

\section{Análise dos vestígios líticos}

A análise preliminar se limitou ao tipo de matéria-prima utilizada em sua elaboração e a classificação morfológica dos vestígios líticos.

Foram coletados 174 vestígios líticos, derivados de atividades de lascamentos. Em relação ao tipo de matéria-prima, 142 foram elaborados com rochas silicificadas (grupo dos silexitos); 1 
vestígio em quartzo hialino; 30 vestígios em quartzo e 1 vestígio em arenito. Em relação à análise morfológica foi possível obter as seguintes informações: 34 vestígios correspondem a núcleos; 85 vestígios pertencem a categoria lasca; 14 vestígios são instrumentos; 39 vestígios são estilhas; 1 vestígio é um batedor e 1 vestígio é um alisador.

A maior parte do acervo apresentava líticos em silexito (núcleos, lascas e estilhas) que foram lascadas pela técnica da percussão direta, visando à obtenção de um gume que facilitasse sua utilização na retirada dos alimentos através de cortes e raspagens. Essa proporcionalidade é um indício de possíveis atividades de lascamentos efetuadas in situ. Os 14 instrumentos eram compostos por raspadores plano-convexos ou raspadores laterais (Figuras 5 e 6), além de micro raspadores (lascas retocadas).

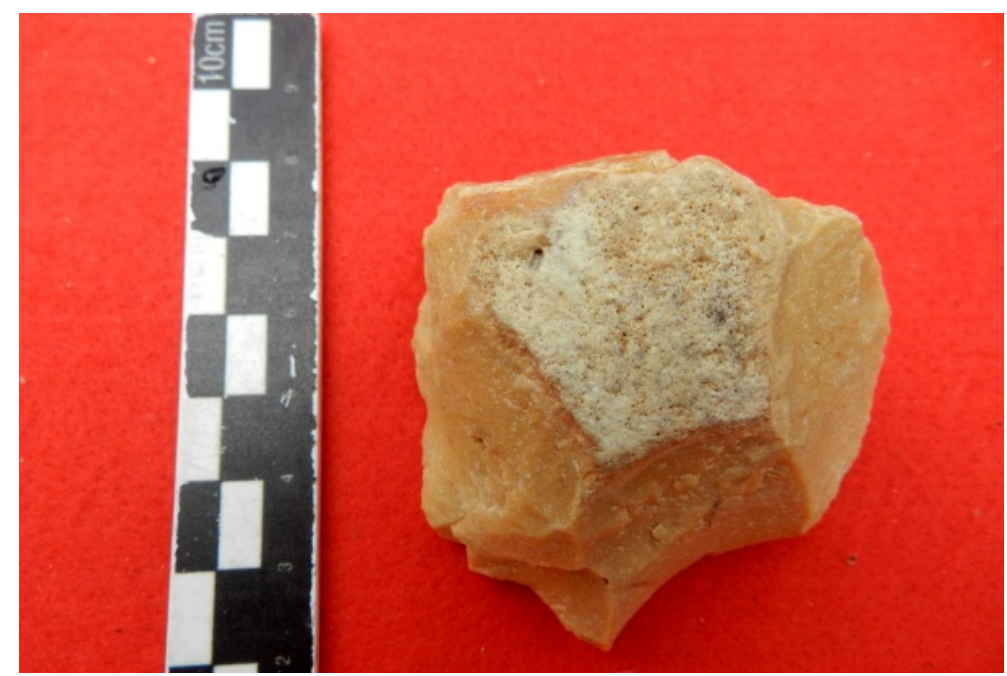

Figura 5: Instrumento (raspador plano-convexo em silexito) - - Sítio Arqueológico Lagoa da Jurema - Açu - RN. Fonte: Santos Júnior, 2015.

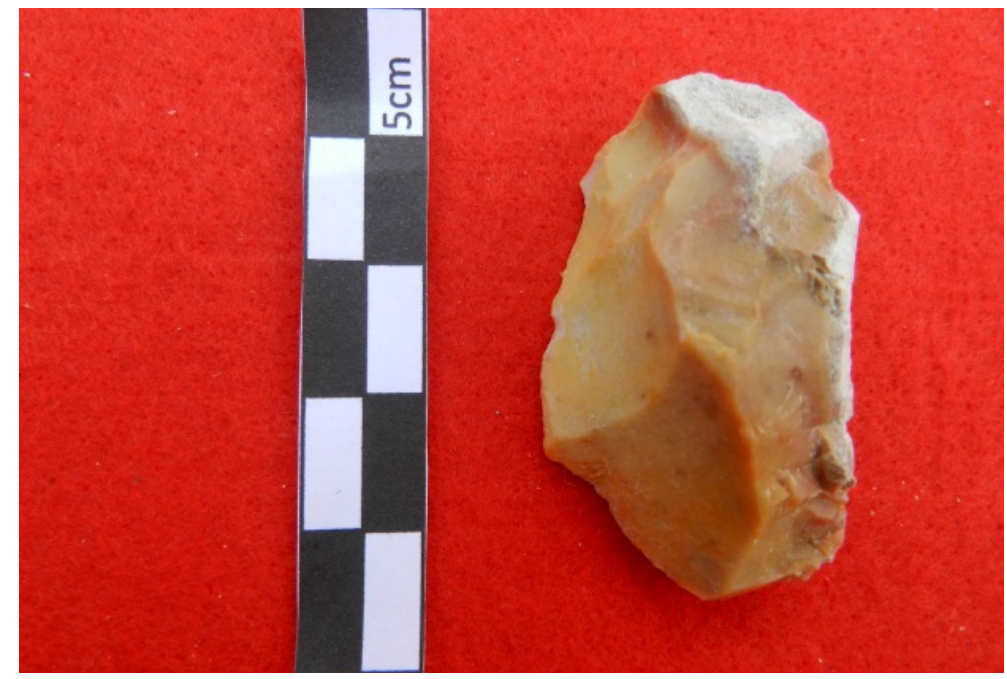

Figura 6: Instrumento (raspador lateral em silexito) - Sítio Arqueológico Lagoa da Jurema - Açu - RN. Fonte: Santos Júnior, 2015. 


\section{Vestígios cerâmicos}

Foram identificados somente 5 fragmentos cerâmicos, todos em nível de superfície, já bastante lixiviados, onde somente 1 fragmento de borda permitiu obter dados sobre sua morfologia. Os antiplásticos dos vestígios apresentavam argilas misturadas com areia, associadas com partículas de quartzo e a queima era completa (Figuras 7 e 8).

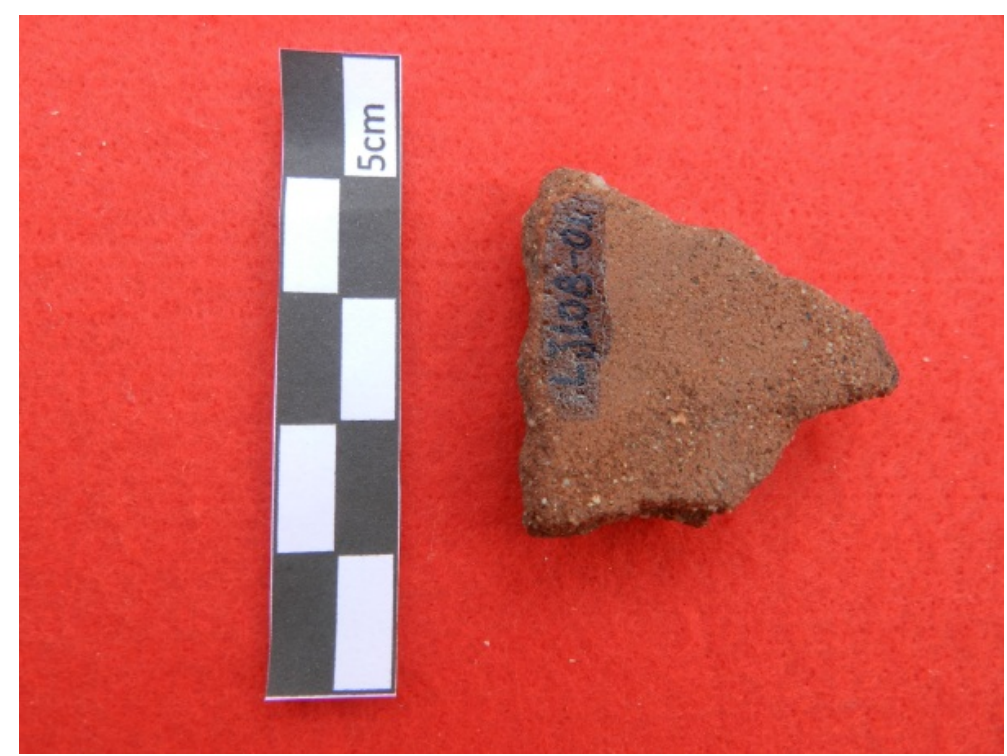

Figura 7: Exemplo de fragmento cerâmico coletado; Sítio Arqueológico Lagoa da Jurema - Açu - RN. Fonte: Santos Júnior, 2015.

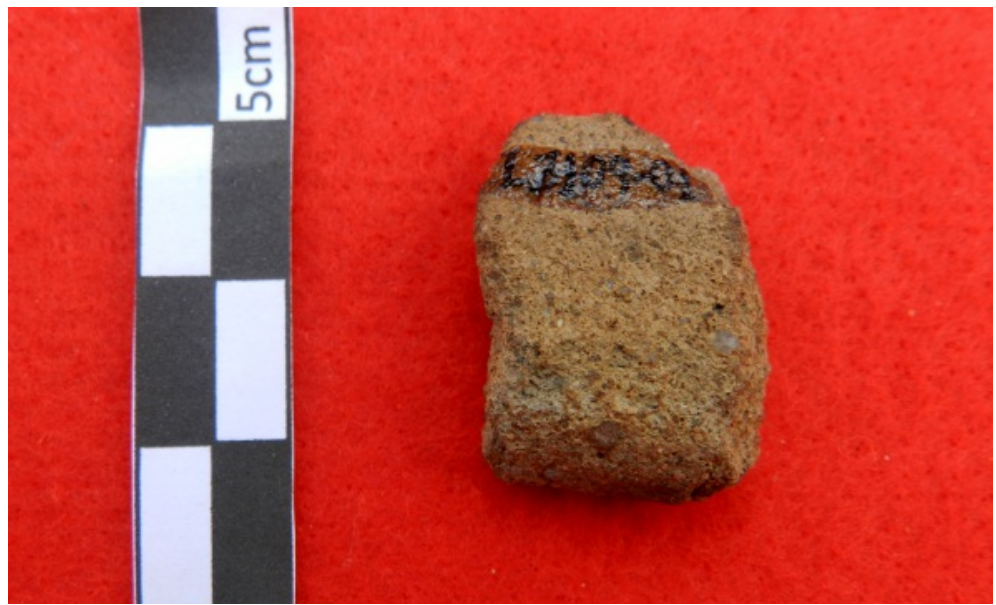

Figura 8: Fragmento cerâmico (borda) - Sítio Arqueológico Lagoa da Jurema - Açu - RN. Fonte: Santos Júnior, 2015. 


\section{Vestígios em Louça}

Foi coletado somente 1 vestígio arqueológico de fragmento de louça, característico da faiança fina inglesa com padrão de decoração floral policromo (Figura 9). Essa decoração é pintada a mão, tem como característica a temática de flores e possui o predomínio das cores verde, rosa, azul e vermelho. Seu período de produção é datado entre os anos de 1820 e 1840 (Caldarelli, 2003). A sua presença no local talvez seja devido a existência de residências próximas, além da lagoa ser frequentada, eventualmente, por vaqueiros e caçadores.

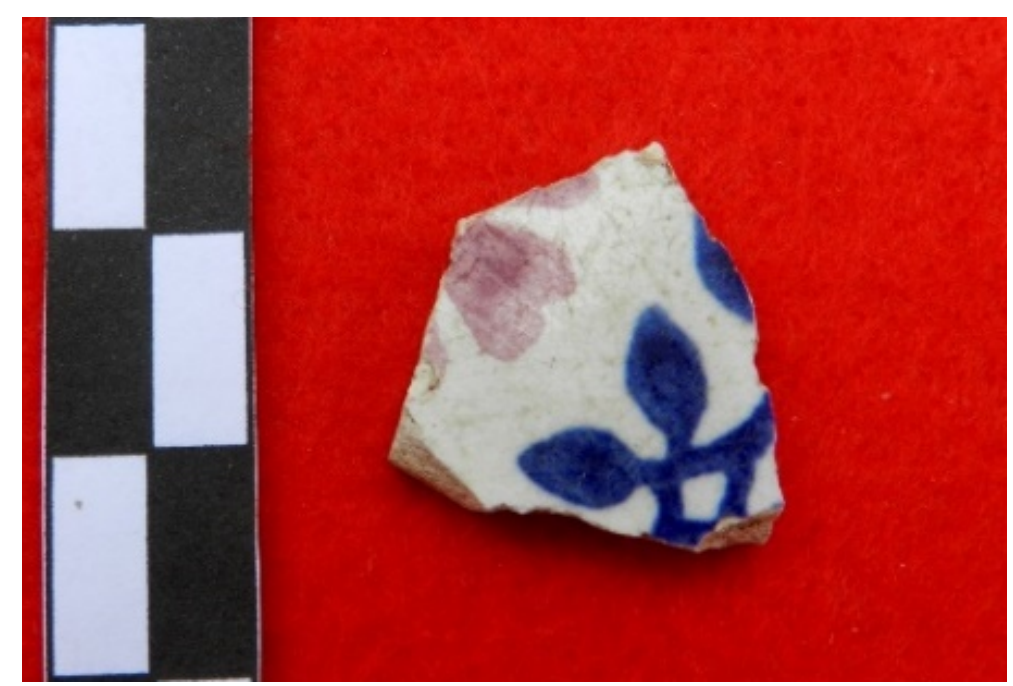

Figura 9: Fragmento de louça (faiança fina) - Sítio Arqueológico Lagoa da Jurema - Açu - RN. Fonte: Santos Júnior, 2015.

\section{Aspectos teóricos de vestígios culturais e sítios arqueológicos na paisagem}

Em se visando entender o processo de deposição espacial dos vestígios arqueológicos na Lagoa da Jurema, fez-se necessário observar alguns conceitos teóricos sobre a ocupação humana pretérita naquele espaço correspondente a recorrência dos padrões de assentamentos.

Para Binford (1968), dependendo do tipo de atividade desempenhada pelos grupos humanos de uma determinada área, o padrão de assentamento pode ter conotações residenciais ou de acampamentos. As áreas tidas como residenciais seriam núcleos de atividades principais para a subsistência dos grupos, como processamento, manufatura e manutenção. As áreas de acampamentos serviriam como base de atividades extrativas. Nas estratégias de relações espaciais entre os sítios, os elementos ambientais necessários a manutenção dos grupos, a 
observação dos tipos de vestígios arqueológicos e perfis tecnológicos desses sítios, podem auxiliar na classificação da tipologia desses sítios.

Basicamente, essa classificação deve utilizar como um dos critérios fundamentais a utilização do espaço geoambiental em três níveis: A utilização do espaço dentro da moradia, dentro da aldeia e a utilização diferencial dos diversos microambientes ou nichos ecológicos dentro do território disponível ao grupo e em estações distintas. Ante esses pressupostos, os procedimentos arqueológicos estavam baseados em termos de técnicas a serem empregadas, principalmente na distribuição e análise espacial dos sítios, que teria como função a recuperação de informação sobre as relações espaciais arqueológicas e estudo das consequências espaciais resultantes da atividade humana dentro de assentamentos, sistemas de assentamentos e seu entorno natural, adotando três categorias de análise dessa espacialidade: micro, semi-micro e macro ${ }^{3}$. Dessa forma, a interpretação da paisagem onde estão inseridos os vestígios arqueológicos é realizada levando-se em consideração os vários níveis de contexto e escalas utilizadas, que vai desde o micro até o macro de um assentamento, onde o espaço micro é o ambiente do sítio escavado ou documentado e o espaço macro pode ser estendido pela região de captação de recursos e mobilidade do grupo (Farias 2005; Miller, 1988; Clarke, 1977).

Dessa forma, é importante ressaltar que o estabelecimento do padrão e do sistema de assentamento é um exercício teórico que engloba interrelações com variáveis ecológicas, espaciais e arqueológicas, que auxiliam no entendimento da distribuição e implantação dos sítios como um todo na paisagem arqueológica (Boado, 1991; Fagundes E Piuzana, 2010). Seguindo essa linha de raciocínio, os sítios devem ser vistos em diferentes níveis de análise espacial, tanto em termos de microambiente relacionados ao assentamento em si, quanto em termos de macroambiente, através do estudo comparativo entre assentamentos distribuídos na paisagem (Chang, 1968).

Outras variáveis de cunho fisiográfico e arqueológico, de acordo com os objetivos da pesquisa, também podem ser observados para identificação dos padrões de assentamento de uma

\footnotetext{
${ }^{3}$ Segundo Clarke (1977), o nível micro diz respeito ao interior ou centro do sítio, às estruturas interiores, abrigos, casas, cemitérios, templos, entre outros. O nível semi-micro é aquele que compõe o conjunto das estruturas do interior do sítio e das suas relações com os arredores imediatos. Os modelos arquitetônicos e urbanísticos devem ser levados em conta, e os aspectos culturais e sociais assumem preponderância sobre os econômicos. O nível macro diz respeito às relações do sítio com a geografia, as paisagens, os relevos, o clima e às adaptações econômicas e culturais das sociedades com estes. Esta escala envolve as questões de tempo, distância e energia dispendida para exploração do meio ambiente. Os fatores econômicos predominam sobre os demais nos estudos deste nível.
} 
determinada região, tais como: a altimetria dos sítios, a fitogeografia, a área abrangida de ocupação dos sítios, os tipos de sítios, a distância deles até a água, as fontes de água utilizadas, cronologia obtida a partir da análise radiocarbônica e de termoluminescência, a inserção no modelado do terreno, a orientação solar, os ventos predominantes e o campo de visão (Corteletti, 2007).Não são muitas variáveis a serem trabalhadas?

\section{A distribuição espacial no sítio arqueológico Lagoa da Jurema}

A distribuição espacial do material lítico, em nível de superfície, mostra uma concentração mais intensa dos vestígios, a partir do local da sondagem 03 e a Leste do sítio (Figura 10), o que sugere três inferências geoambientais no processo deposicional dos vestígios culturais:

a) a primeira está vinculada a questão altimétrica, haja vista que o local do sítio possui cotas altimétricas mais baixas (em relação a maior parte do entorno) com um perfil de declividade na direção Norte (Figura 11);

b) a segunda diz respeito a incidência de uma quantidade maior de afloramentos de arenitos, que funcionaria como um vetor de retenção natural no carreamento de vestígios arqueológicos, tanto para as cotas altimétricas mais baixas, assim como no lado Leste do sítio;

c) a possibilidade de carreamento do material lítico pelo lado Leste, em direção as cotas altimétricas mais baixas do sítio.

Esse carreamento, em parte foi barrado pelos afloramentos areníticos situados na parte mais elevada. 


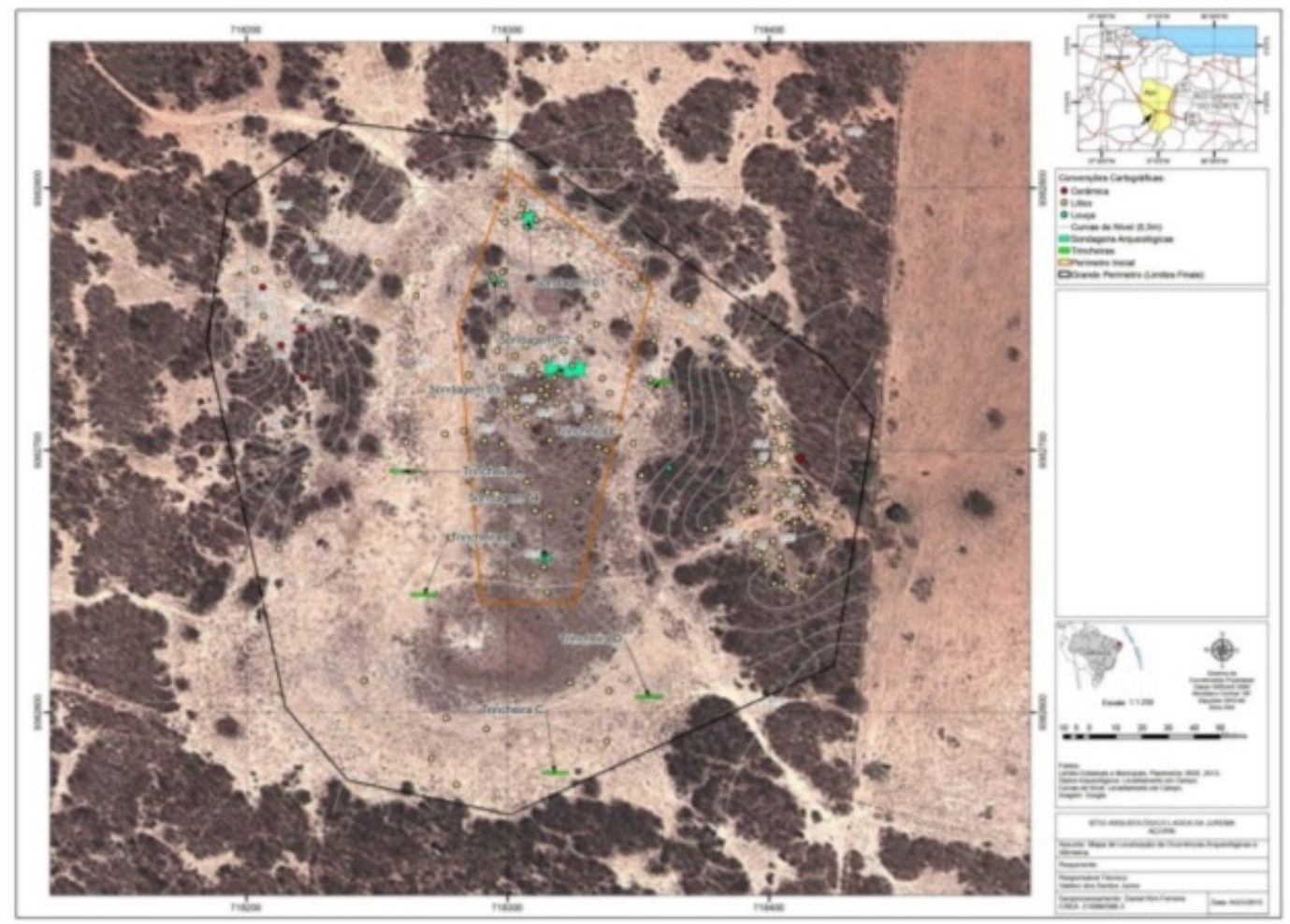

Figura 10: Altimetria dos vestígios arqueológicos nos diversos setores do sítio arqueológico Lagoa da Jurema - município de Açu - RN. Fonte: Daniel Kim, (2015).

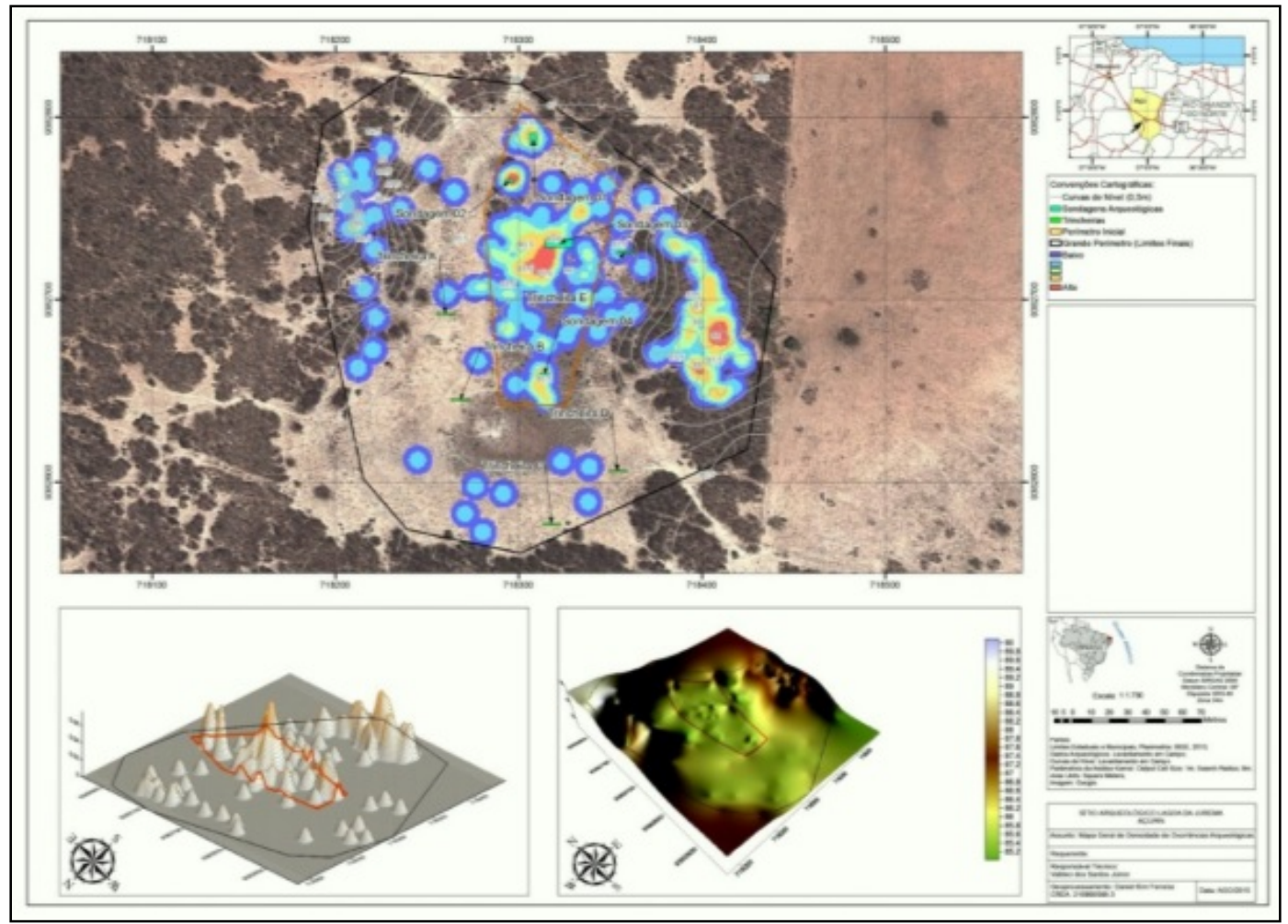

Figura 11: Densidade dos vestígios arqueológicos nos diversos setores do sítio arqueológico Lagoa da Jurema - município de Açu - RN. Fonte: Daniel Kim, (2015). 


\section{Fatores deposicionais e pós-deposicionais}

A predominância quase absoluta dos vestígios arqueológicos do sítio está composta por líticos originários de matérias-primas advindas de rochas silicificadas pertencentes ao grupo do silexitos. Esses processos de silicificação estão vinculados a níveis estratigráficos geológicos, feições genéticas provenientes de processos controladas pelo clima com a formação de silcretes $^{4}$ ou de cunho hidrotermal que, através de fluxos líquidos nas falhas geológicas e outros fatores tectônicos, originam as rochas silicosas, ou seja, formadas predominantemente por sílica, onde os grãos de quartzo e o cimento possuem a mesma composição química (SIO2 sílica).

Grande parte dos cursos d'água na região do Vale do Açu tem trechos controlados por alinhamentos estruturais, como falhas ou fraturas no domínio de rochas cristalinas (fonte, ano). Essas fraturas criam uma porosidade secundária responsável pela infiltração das águas de superfície e circulação das águas subterrâneas, o que explicaria a diagênese dessas rochas silicificadas na região, que serviram como fontes de matérias-primas para os grupos pretéritos.

Entretanto, para se entender a presença desses vestígios líticos no sítio, será necessário observar também os processos de formação desses registros arqueológicos que possuem componentes de origem cultural e natural, incluindo suas fases sin-deposicional e pósdeposicional.

\section{Fatores culturais}

Os fatores iniciais de deposição dos registros arqueológicos estavam ligados diretamente à organização espacial e social dos indivíduos pretéritos, que participaram das atividades produtivas vinculadas essencialmente aos lascamentos líticos. Esses vestígios líticos indicam a produção tecnológica de instrumentos com objetivo de cortar, raspar ou perfurar para suprir necessidades de subsistência dos grupos pretéritos, vinculadas principalmente à caça da pequena fauna local.

\footnotetext{
${ }^{4} \mathrm{O}$ termo silcrete é utilizado para se referir a materiais silicificados de diferentes estruturas e texturas, independente de sua origem e são produzidos pela cimentação de materiais não consolidados (sedimentos, saprólito, solos) por várias formas de sílica secundária, incluindo opala, quartzo criptocristalino ou quartzo cristalizado. Para isso, usualmente são necessárias condições supergênicas, particularmente situadas acima da zona freática ou em ambiente de formação de solos (Araújo, 1991).
} 
Após a deposição e abandono desses vestígios líticos (incluindo núcleos utilizados, lascas e instrumentos) no sítio, alguns fatores culturais - pós-deposicionais - alteraram parte desse estado original. Dentre esses fatores podem ser mencionados algumas intervenções antrópicas, visando ao uso e ocupação da terra no período histórico mais recente:

a) Embora os solos existentes no local, associados com a proximidade dos afloramentos de arenitos não favoreçam plantios agrícolas em grande escala, é possível que alguns setores da Lagoa da Jurema tenham sido utilizados para atividades sazonais de sequeiro, tais como plantio de milho e feijão. Como geralmente esse plantio envolve a utilização de maquinários e implementos no revolvimento dos sedimentos superficiais, é possível que parte dos vestígios líticos tenha sofrido marcas e/ou alterações em seu estado original de deposição;

b) Outro fator de intervenção cultural contemporâneo está associado à extração de madeiras de pequeno porte da caatinga, como a Jurema (mimosa hostilis), por exemplo, que é bastante utilizada como matéria-prima para queima em fornos de padarias e nas olarias para produção de telhas e tijolos, no Vale do Açu. Durante as atividades extrativistas da madeira, os vestígios líticos, tanto em nível de superfície como em nível de subsuperfície, são deslocados substancialmente sofrendo alterações espaciais e mutilações antrópicas;

c) Embora a maior parte dos vestígios líticos seja totalmente desconhecida quanto a sua gênese pelos caçadores contemporâneos eventuais que frequentam eventualmente a Lagoa da Jurema, alguns instrumentos líticos podem ter sido coletados assistematicamente, em nível de superfície, principalmente pontas de projéteis e as lâminas de machado e almofarizes (com percutores) polidos, devido às lendas seculares sertanejas da "Pedra do Corisco";

d) Um último fator pós-deposicional são as próprias intervenções arqueológicas realizadas pelos arqueólogos/equipe, na área do sítio e de seu entorno, através de prospecções e escavações que englobam as sondagens realizadas em nível de superfície e subsuperfície que, por si só, já alteram o estado de deposição original in situ dos vestígios pretéritos.

\section{Fatores naturais}

Os fatores naturais de formação dos registros arqueológicos do sítio podem ser classificados em dois grupos: os de origem biológica e os de origem física. 


\section{Fatores biológicos}

Os fatores de origem biológica estão vinculados a bioturbação com características de fitoturbação e zooturbação.

Quanto à fitoturbação, foi possível observar sua influência, ora no sentido vertical, ora no sentido horizontal, nas 04 sondagens realizadas no sítio, onde as raízes vegetais da caatinga arbustiva, principalmente a Jurema (Mimosa hostilis), atingiram a profundidade de até $15 \mathrm{~cm}$. A ação das raízes através de movimentação e aprofundamento, geralmente pode causar o deslocamento em direções variadas de artefatos, estruturas ou sedimentos, alterando a disposição original dos vestígios culturais, assim como os incêndios naturais podem se estender até as raízes em subsuperfície das árvores do entorno, podendo vir a alterar as idades dos carvões nos níveis estratigráficos (Araújo, 1999).

Quanto à zooturbação, os vestígios culturais podem ter sido afetados pela presença de animais contemporâneos de criação, tais como bovinos, bodes e cabras, que fazem suas trilhas na caatinga, pisoteando os líticos e os fragmentos cerâmicos porventura existentes, deslocando de seus estados primários de deposição.

\section{Fatores físicos}

Os fatores naturais de origem física que podem ter afetados a deposição primária dos vestígios arqueológicos geralmente estão ligados aos aspectos geomorfológicos, geológicos, climáticos, hidrográficos, pedológicos e fitogeográfico. A principal influência da geologia e do clima está ligada ao processo do intemperismo físico que ocorre na área em que está situada a Lagoa da Jurema, onde a alternância de períodos chuvosos (invernos) com períodos quentes (verão) provoca alterações (carreamentos) dos sedimentos do solo em nível superficial (SANTOS JÚNIOR, 2013).

Em algumas áreas da Lagoa, principalmente no setor Sul, as atividades pluviométricas podem ter auxiliado no deslocamento espacial desses sedimentos superficiais para cotas altimétricas mais baixas, levando consigo vestígios líticos. Foi possível observar um carreamento dessa natureza que apresentou sedimentos (associados com material lítico) com uma intensidade maior de fragmentos de cascalheiras que foram retidos naturalmente pelos afloramentos de arenitos existentes na própria Lagoa. 
Já os efeitos da hidrografia, nos processos de formação dos registros arqueológicos da área da Lagoa da Jurema, estão vinculados à própria dinâmica pluvial e fluvial da lagoa que possui irregularidade hídrica, alternando períodos de estiagem com períodos torrenciais, afetando diretamente as suas margens, atingindo consequentemente, os vestígios arqueológicos, alterando, em parte, a disposição espacial primária dos assentamentos.

De forma sintética, os processos culturais e naturais que atuaram na formação dos registros arqueológicos da Lagoa da Jurema podem ser observados no quadro 1:

Quadro 1: Processos culturais e naturais de formação do registro arqueológico no sítio arqueológico Lagoa da Jurema, município de Açu-RN.

\begin{tabular}{|c|c|c|c|c|}
\hline Processos & Momento & \multicolumn{2}{|c|}{ Investigação } & Causas \\
\hline \multirow[t]{6}{*}{ Culturais } & \multirow[t]{2}{*}{ Sin-deposicional } & \multirow[t]{2}{*}{$\begin{array}{l}\text { Estratégias } \\
\text { culturais }\end{array}$} & Etnoarqueologia & $\begin{array}{l}\text { Organização espacial } \\
\text { e social }\end{array}$ \\
\hline & & & Tecnologia & Subsistência \\
\hline & \multirow[t]{4}{*}{$\begin{array}{l}\text { Pós- } \\
\text { deposicional }\end{array}$} & \multirow[t]{4}{*}{$\begin{array}{l}\text { Ações } \\
\text { históricas }\end{array}$} & $\begin{array}{l}\text { Uso e ocupação da } \\
\text { terra }\end{array}$ & Agropecuária \\
\hline & & & \multirow{2}{*}{$\begin{array}{l}\text { Ações } \\
\text { assistemáticas }\end{array}$} & Coleta assistemática \\
\hline & & & & Mutilação \\
\hline & & & Arqueologia & $\begin{array}{l}\text { Intervenções } \\
\text { arqueológicas }\end{array}$ \\
\hline \multirow[t]{4}{*}{ Naturais } & \multirow[t]{4}{*}{$\begin{array}{l}\text { Sin-pós- } \\
\text { deposicional }\end{array}$} & Biológica & Bioturbação & $\begin{array}{l}\text { Fitoturbação } \\
\text { Zooturbação }\end{array}$ \\
\hline & & \multirow[t]{3}{*}{ Física } & \multirow[t]{3}{*}{ Geomorfológico } & Geologia \\
\hline & & & & Clima \\
\hline & & & & Hidrografia \\
\hline
\end{tabular}

Fonte: Santos Júnior,(2015), adaptado de Pedroza (2011).

\section{Fontes de matérias-primas - líticos}

A utilização pretérita do espaço do sítio pôde incluir, possivelmente, grupos de caçadorescoletores que podem ter ocupado áreas de acampamentos sazonais (extração de matériaprima, acampamentos de curta e longa duração), como a locais com atividades cronológicas e funcionais mais intensivas, como as oficinas líticas, por exemplo. Nesses espaços, os materiais utilizados para os lascamentos poderiam ser obtidos em jazidas situadas nas proximidades, o que evitaria grandes deslocamentos dos caçadores-coletores para aquisição dela.

Os grupos de caçadores-coletores naturalmente adotavam estratégias nas escolhas para aquisição dessa matéria-prima rochosa para elaboração de seus instrumentos. Lemos (2008), 
relaciona alguns dos fatores e estratégias que influenciavam diretamente nessas escolhas: a) abundância de matéria-prima disponível nas proximidades, onde as estratégias de aquisição mostram que essas fontes podem ser consideradas "locais", se a mobilidade do grupo ocorre dentro de um raio de $5 \mathrm{~km}$ de um sítio; b) qualidade de lascamento da matéria-prima localmente disponível; c) qualidade funcional da matéria-prima localmente disponível; d) necessidade técnica e restrição funcional; e) conhecimento da fonte mais distante; f) contexto socioeconômico; g) custo na aquisição da matéria-prima; h) tradição do grupo: a recorrente preferência por uma matéria-prima em particular.

Essas fontes de matérias-primas de rochas silicosas são abundantes e podem ser facilmente localizadas nos tabuleiros, riachos e nas paleocascalheiras existentes nos municípios do Vale do Açu, na Microrregião de Angicos e da Serra de Santana. Portanto, a presença desse material lítico silicoso junto aos afloramentos de arenitos existentes na Lagoa da Jurema se explica pela proximidade geográfica dessas fontes.

\section{Fontes de matérias-primas - Cerâmica}

As fontes de matérias-primas argilosas são bastante comuns no município de Açu-RN, conhecido pela presença constante de Olarias para produção de telhas e tijolos. No Nordeste brasileiro é bastante conhecida as "telhas de Açu" sendo vendida principalmente para as capitais nordestinas. A maior parte das fontes está situada as margens do rio Piranhas-Açu que, periodicamente (nos períodos de bons invernos) são inundadas pelas cheias do rio. A Lagoa da Jurema dista cerca de $14 \mathrm{~km}$, na direção Leste, para as principais fontes argilosas do rio Piranhas Açu.

\section{Discussão dos resultados}

Os grupos pretéritos que se estabeleceram no espaço geográfico do sítio arqueológico deixaram vestígios culturais que evidenciam ocupações diacrônicas do local para atividades de lascamentos antrópicos de matérias-primas próximas, envolvendo principalmente as rochas silicificadas. 
A ausência de estruturas antrópicas, tais como fogueiras, por exemplo, nas sondagens e trincheiras, pode evidenciar a utilização do espaço da Lagoa para atividades de caráter predominantemente funcionais, vinculados à elaboração de ferramentas líticas expeditas.

Foi observada a produção de 16 instrumentos líticos que, analisadas a partir da relação proporcional com o quantitativo expressivo de núcleos (34) e a quantidade de lascas geradas (85), demonstra de forma inequívoca a utilização do local com essa finalidade produtiva. A quantidade de estilhas (39) pode sugerir também, além das atividades de lascamentos, possíveis carreamentos pluviais periódicos desses vestígios arqueológicos com o auxílio da altimetria.

As lascas, em sua grande maioria, são brutas que apresentam córtex e bulbo, seguido das lascas descorticadas. Os núcleos podem ser divididos em dois tipos: artefatos que tiveram apenas uma ou duas retiradas (representando maior quantidade dentre os existentes - talvez demonstrando a intenção de se observar a matéria-prima) e, em menor número os núcleos esgotados. Os instrumentos são predominantemente raspadores laterais.

Dos 5 fragmentos cerâmicos, nenhum deles permitiu uma análise dos atributos, haja vista que todos foram considerados residuais, já bastante lixiviados. Todos eles tinham a mesma técnica de manufatura (acordelada) e queima completa. Não foi possível caracterizar qualquer possível cronologia a esses fragmentos, mesmo que, de forma indireta, pudessem pertencer inclusive a grupos contemporâneos que utilizam esporadicamente a Lagoa.

\section{Considerações Finais}

Os resultados das prospecções e escavações arqueológicas, além das análises de laboratório dos vestígios culturais coletados no sítio Lagoa da Jurema permitem efetuar inferências a respeito do padrão de assentamento pretérito naquele espaço específico.

A intensidade dos vestígios líticos lascados em nível de superfície, assim como sua recorrência exclusiva no mesmo nível, permite supor ocupações temporárias diacrônicas daquele espaço por grupos humanos pretéritos para obtenção de água, além da caça da pequena fauna com a utilização de instrumentos líticos. A recorrência artefatual com pouca variabilidade nas técnicas de execução (percussão direta) evidencia a permanência de posturas pelos autores repassados aos seus descendentes que reproduziam essas técnicas. A preferência na 
elaboração de raspadores laterais é um indício funcional que reforça a utilização desses instrumentos na caça (pequena fauna) e na possível pesca temporária como estratégia de sobrevivência grupo.

Outro fator a ser destacado é a proximidade das fontes de matérias-primas rochosas utilizadas nos lascamentos, entre os quais eram preferenciais o quartzo e o silexito. A proximidade dessas fontes facilitava a mobilidade dos grupos pretéritos na captação desses materiais, devido a abundância dessas fontes e a facilidade geográfica para sua obtenção. Esse detalhe, provavelmente, auxiliaria na permanência dos grupos na paisagem arqueológica com padrões de assentamentos mais prolongados, daí a recorrência dessas atividades de lascamentos em diversos lugares da região.

\section{Referências}

ARAújo, A. G. de M. 1999. As geociências e suas implicações em teoria e métodos arqueológicos. Revista do Museu de Arqueologia e Etnologia, São Paulo, suplemento 03, p. 3545.

ARAÚJO, A. G. de M. 1991. As rochas silicosas como matéria-prima para o homem préhistórico: variedades, definições e conceitos. Revista do Museu de Arqueologia e Etnologia, volume 01, São Paulo, p. 105-111.

BINFORD, L. R. 1968. Some comments on historical precessual archaeology, South- Western Journal of Anthropology. 24: p. 267-275.

BOADO, F. C. 1991. Construcción social del espacio y reconstrucción arqueológica del paisaje. Boletín de Antropología Americana, 24, p. 5-29.

CALDARELLI, S. B. 2003. Arqueologia do Vale do Paraíba paulista. SP-070 Rodovia Carvalho Pinto, DERSA Desenvolvimento Rodoviário SA, IPARQ Instituto de Pesquisas em Arqueologia, UNISANTOS, Universidade Católica de Santos, São Paulo, Brasil, 244p,

CHANG. K. 1968. Toward a science of pré-historic society. In: CHANG.K.C (ED) Settlement archaeology. Palo Alto, National Press Books, p. 1-9.

CLARKE, D. L. 1977. Spatial Information in Archaeology. In: Spacial archaeology, London and New York, Academic Press, 1977. p. 1-32.

CORTELETTI, R. 2007. Onde, como e quando? Construindo um padrão de assentamento dos sítios arqueológicos na região de Caxias do Sul, RS. Artigo publicado nos anais do XIV Congresso da $\mathrm{SAB}$ e I Congresso Internacional de Arqueologia da SAB, Florianópolis, Santa Catarina, Brasil. p. 01-25. 
FAGUNDES, M. \& PIUZANA, D. 2010. Estudo teórico sobre o uso do conceito de paisagem em pesquisas arqueológicas. Revista latino-americana de ciencias soc.niñez juv 8(1): p. 205-220.

FARIAS, D. S. E. 2005. Distribuição e padrão de assentamento - propostas para os sítios da tradição umbu na encosta de Santa Catarina. Tese de doutorado, Curso de Pós-Graduação em História, Pontifícia Universidade Católica do Rio Grande do Sul, 367 p.

LEMOS, L. 2008. O sítio do Areal e a região do Rincão do Inferno: a variabilidade gestual e o modelo locacional para a fronteira Oeste do Rio Grande do Sul. Dissertação de mestrado, programa de pós-graduação em arqueologia, Museu de arqueologia e etnologia, Universidade de São Paulo. 155 p.

MILLER, T. O. 1988. Homem, ambiente e sistema: para uma arqueologia antropológica e intersubjetiva. Arquivos do Museu de História Natural da UFMG. v. VIII. Belo Horizonte: UFMG.

PEDROZA, I. 2011. O registro arqueológico de grupos caçadores-coletores em ambientes semiáridos: uma abordagem geoarqueológica dos sítios Várzea do Boi, Tauá-CE. Dissertação (Mestrado em Arqueologia) - Programa de Pós-Graduação em Arqueologia, Universidade Federal de Pernambuco. 204 p.

SANTOS JÚNIOR, V. 2013. Arqueologia da paisagem : proposta geoambiental de um modelo explicativo para os padrões de assentamentos do Enclave Arqueológico Granito Flores, microrregião de Angicos (RN). Tese (Doutorado) - Universidade Federal de Pernambuco. CFCH. Programa de Pós-Graduação em Arqueologia. 